\title{
Body mass estimation in amphicyonid carnivoran mammals: A multiple regression approach from the skull and skeleton
}

\author{
Borja Figueirido, Juan A. Pérez-Claros, Robert M. Hunt, Jr., and Paul Palmqvist \\ Acta Palaeontologica Polonica 56 (2), 2011: 225-246 doi: http://dx.doi.org/10.4202/app.2010.0005
}

The body masses of sixteen species of amphicyonids (Mammalia, Carnivora, Amphicyonidae) from the New and Old World were estimated on the basis of 86 osteological variables measured from the craniodental $(\mathrm{N}=44)$ and postcranial $(\mathrm{N}=42)$ skeleton of living species of Canidae and Ursidae. Given the absence of complete and well preserved skeletons of amphicyonids in the fossil record, multiple regression functions were derived separately from measurements taken from the mandible, the cranium and the major limb bones. The accuracy of the regression functions was evaluated using the percentage prediction error and the percentage standard error of the estimates. Mass values were calculated with these equations using measurements taken in adult individuals from a number of daphoenine and amphicyonine species. Results obtained show that three distinct size classes of amphicyonids emerged through the evolutionary history of the "beardog" family and that these size classes correlate with presumably different ecomorphs. Quantitative estimates of body size of amphicyonids are critical for deciphering the paleobiology of this poorly understood family of large fissiped carnivorans and can be used for placing it within a broader ecological context.

Key words: Mammalia, Carnivora, Amphicyonidae, body mass, multiple regression, skull, skeleton.

Borja Figueirido [ㅍrancisco.figueirido@uv.es], Juan Antonio Pérez-Claros [ohnny@uma.es ], and Paul Palmqvist [Paul.Palmqvist@uma.es] Departamento de Ecología y Geología. Facultad de Ciencias, Universidad de Málaga, Campus de Teatinos s/n. 29071 Málaga, Spain; Robert M. Hunt, Jr. [rhunt2@unl.edu], Department of Geological Sciences, University of Nebraska, Lincoln, NE 68588-0514.

This is an open-access article distributed under the terms of the Creative Commons Attribution License (for details please see creativecommons.org), which permits unrestricted use, distribution, and reproduction in any medium, provided the original author and source are credited. 
PoF Full text (631.4 kB) 